\title{
Bornavirus immunopathogenesis in rodents: models for human neurological diseases
}

\author{
Thomas Briese ${ }^{1}$, Mady Hornig ${ }^{1}$ and W Ian Lipkin*,1 \\ ${ }^{1}$ Laboratory for the Study of Emerging Diseases, Department of Neurology, 3101 Gillespie Neuroscience Research \\ Facility, University of California, Irvine, California, CA 92697-4292, USA
}

\begin{abstract}
Although the question of human BDV infection remains to be resolved, burgeoning interest in this unique pathogen has provided tools for exploring the pharmacology and neurochemistry of neuropsychiatric disorders potentially linked to BDV infection. Two animal models have been established based on BDV infection of adult or neonatal Lewis rats. Analyis of these models is already yielding insights into mechanisms by which neurotropic agents and/or immune factors may impact developing or mature CNS circuitry to effect complex disturbances in movement and behavior.
\end{abstract}

Keywords: Borna disease virus; neurotropism; humoral and cellular immune response; $\mathrm{Th}_{1}-\mathrm{Th}_{2}$ shift; apoptosis; dopamine; cytokines

\section{Introduction}

Borna disease virus (BDV), the prototype of a new family, Bornaviridae, within the nonsegmented negative-strand RNA viruses, infects the central nervous system (CNS) of warmblooded animals to cause behavioral disturbances reminiscent of autism, schizophrenia, and mood disorders (Lipkin et al, 1995). BDV is not lytic in vitro or in vivo, replicates at lower levels than most known viruses and is dissimilar in nucleic acid and protein sequence to other infectious agents (de la Torre, 1994; Schneemann et al, 1995). The molecular biology of BDV is unusual in many respects including a nuclear localization for replication and transcription, overlap of open reading frames and transcription units, posttranscriptional modification of subgenomic RNAs, and marked conservation of coding sequence across a wide variety of animal species and tissue culture systems. Natural infection has been confirmed in horses, sheep, cattle, dogs, birds and cats. Primates can be infected experimentally (Stitz et al, 1980). This wide host range suggests that humans are likely to be susceptible to BDV infection; however, there is no consensus concerning the role of BDV in human disease. Although some investigators report an increased prevalence of BDV infection in mood

\footnotetext{
${ }^{*}$ Correspondence: WI Lipkin

Received 3 March 1999; revised 21 May 1999; accepted 29 June 1999
}

disorders and schizophrenia (Amsterdam et al, 1985; Bode et al, 1988, 1992, 1993; Fu et al, 1993; Kishi et al, 1995; Waltrip II et al, 1995), others have not succeeded in replicating these findings (Iwata et al, 1998; Kubo et al, 1997; Lieb et al, 1997; Richt et al, 1997). Here we review two rodent models of BDV infection that provide insight into mechanisms by which neurotropic viruses may impact CNS development and function to effect complex disturbances in behavior.

\section{Neurotropism and persistence}

Neurotropism of BDV is likely to be multifactorial. The integrity of the humoral immune response is critical to restriction of virus to neural compartments (Stitz et al, 1998); however, replication is still higher in limbic structures in animals with compromised humoral immunity; thus, additional factors must contribute to neurotropism. One means by which preferential replication of BDV in limbic structures might occur is through restricted distribution of the enzymatic machinery required for its lifecycle. The phosphoprotein of BDV $(\mathrm{P})$ is predicted by analogy to phosphoproteins of other nonsegmented negative-strand RNA viruses to serve as a transcriptional activator (de la Torre, 1994; Schneemann et al, 1995). It also contains potent nuclear localization signals (Shoya et al, 1998; 
Schwemmle et al, 1999) and interacts with two other BDV proteins, the nucleoprotein and Xprotein to affect their intracellular distributions (Schwemmle et al, 1998). Thus, $\mathrm{P}$ may also have additional functions related to nucleocasid assembly and/or protein trafficking within the cell. BDV P is phosphorylated primarily by the epsilon isotype of protein kinase C (PKCe) (Schwemmle et al, 1997). Interestingly, the regional distributions of $\mathrm{PKC} \varepsilon$ (Saito et al, 1993) and BDV in rat brain (Narayan et al, 1983a) are similar, suggesting the possibility that the localization of $\mathrm{PKC} \varepsilon$, through its phosphorylation effects, may influence the tropism of BDV for limbic circuitry.

In many CNS viral infections, the presence of an intact immune response results in either viral clearance or host mortality. This is not the case in BDV, where infection may persist in the presence of a transient but robust immune response. Persistence may be due to induction of $\mathrm{Th}_{1}$ tolerance. Whereas lymphocytes isolated from brains of acutely infected rats have potent cytolytic activity, lymphocytes from brains of chronically infected rats do not lyse BDV-infected target cells (Sobbe et al, 1997). Induction of BDV-specific tolerance in chronic infection may reflect the timecourse for presentation of viral antigens in the thymus (Rubin et al, 1995). Alternatively, $\mathrm{Th}_{1}$ cells may become anergic or undergo apoptosis due to presentation of BDV antigens in brain without essential costimulatory signals (Karpas et al, 1994; Khoury et al, 1995; Schwartz, 1992). Support for the latter hypothesis is found in the observation that apoptosis of perivascular inflammatory cells is most apparent at 5-6 weeks post infection (p.i.), coincident with the onset of decline in encephalitis (Hatalski et al, 1998a).

In an effort to explore differences in host gene expression during persistent infection that might be linked to tolerance, subtractive cloning methods were applied to analysis of RNA from brains of acute and persistent adult infected rats. The persistently infected rats had a dramatic increase in mRNAs encoding immunoglobulin-a finding that suggested that $\mathrm{Th}_{1}$ tolerance might reflect a $\mathrm{Th}_{1}-\mathrm{Th}_{2}$ shift in the immune response. This hypothesis was confirmed by RNase protection assays that demonstrated a shift in the brain cytokine mRNA profile from $\mathrm{Th}_{1}-\mathrm{Th}_{2}$ cytokines and an isotype switch in peripheral blood from IgG to IgE (Hatalski et al, 1998a,b). Although the enhanced humoral immune response in chronic disease does not promote viral clearance, it may play an important role in limiting viral gene expression (Hatalski et al, 1998a). Complementary work by Hatalski et al (1998b) in the chronic phase of $\mathrm{BD}$ reported increases in intra-CNS production of IgG antibodies that parallel increases of antibodies with neutralizing activity against BDV in peripheral blood. Definitive evidence that humoral immunity contributes to BDV tropism emerged from recent work by Stitz et al where passive transfer of neutralizing antibodies resulted in limitation of viral replication within the CNS (Stitz et al, 1998). Similar results have been reported in other viral systems; for example, passive transfer of virusspecific antibodies limits viral replication in the CNS following infection with murine hepatitis virus type-4 (Buchmeier et al, 1984) or measles virus (Liebert et al, 1990), and induces clearance of virus following infection with rabies (Dietzschold et al, 1992) or Sindbis virus (Levine et al, 1991).

\section{Adult Lewis rat infection}

Bornavirus neuropathogenesis has been studied primarily in adult immunocompetent rodents and ungulates where infection results in dramatic disturbances in behavior, limbic circuitry, and monoamine neurotransmitter systems. These models are intriguing; however, they are associated with marked CNS inflammation, loss of brain mass and gliosis and may be less relevant to neuropsychiatric diseases than those in neonatally infected rats where BDV induces subtle disturbances of behavior and dysgenesis of the cerebellum and hippocampus without robust inflammatory cell infiltration.

As in autism (Anderson, 1994; Ernst et al, 1997), schizophrenia (Cooper et al, 1991), and mood disorders (Hamner and Diamond, 1996; Kelsoe et al, 1996; Partonen, 1996), disorders of movement and behavior in adult BD rats are linked to distinct changes in CNS dopamine systems (Solbrig et al, 1994, 1995, 1996a,b, 1998) and may be further linked to serotonin abnormalities (Solbrig et al, 1995). The immune-mediated disorder in adult infected rats presents clinically as hyperactivity and exaggerated startle responses 10-14 days after intracerebral infection (Narayan et al, 1983a). The acute phase coincides with infiltration of monocytes into the brain, particularly in areas of high viral burden including the hippocampus, amygdala and other limbic structures (Carbone et al, 1987). Two to three weeks later, rats show high grade stereotyped motor behaviors (the continuous repetition of behavioral elements such as sniffing, chewing, scratching, grooming, and self-biting), dyskinesias, dystonias, and flexed seated postures (Solbrig et al, 1994), in parallel with the widespread distribution of virus in limbic and prefrontal circuits. Five to ten per cent of animals become obese, achieving body weights up to $300 \%$ of normal (Ludwig et al, 1988).

Central dopamine systems of adult-infected BD animals are more sensitive to dopamine agonists and antagonists than normal rats. Infected animals have increased locomotor and stereotypic behavior following administration of the mixed-acting dopamine agonist, dextroamphetamine (Solbrig et al, 1994). Similarly, enhanced locomotion and stereo- 
typies are seen in response to the dopaminergic reuptake inhibitory effects of cocaine, indicating dose-dependent potentiation of dopamine neurotransmission (Solbrig et al, 1998). The movement and behavior disorder is improved following treatment with selective dopamine antagonists; whereas D2-selective antagonists (e.g., raclopride) do not affect locomotor responses in BD rats, high doses of selective D1 antagonists (e.g., SCH23390) and atypical dopamine blocking agents with mixed D1 and D2 antagonist activity such as clozapine selectively reduce locomotor activity in BD rats but not in controls (Solbrig et al, 1994).

HPLC analyses reveal abnormal neurochemistry in adult-infected BD rats. Levels of dopamine and its major metabolite, dihydroxyphenylacetic acid (DOPAC), are reduced in structures that receive dopaminergic terminals including striatum, nucleus accumbens, and olfactory tubercle (Solbrig et al, 1994). Interestingly, although levels of dopamine and DOPAC are also reduced in prefrontal cortex, the ratio of DOPAC to dopamine is increased suggesting enhanced turnover of dopamine in this structure (Solbrig et al, 1996a). Tyrosine hydroxylase-immunoreactive cells are depleted in substantia nigra and ventral tegmental area (tyrosine hydroxylase is the rate limiting enzyme in dopamine synthesis and may be used to identify cells that produce dopamine) (Solbrig et al, 1994). Taken together, these results suggest partial dopaminergic deafferentation with compensatory metabolic hyperactivity in nigrostriatal and mesolimbic dopamine systems. At the receptor level, both pre- and postsynaptic sites of the dopamine transmitter system appear to be damaged in striatum (caudate-putamen and nucleus accumbens). Dopamine uptake sites, as measured by binding of mazindol, are reduced in nucleus accumbens (Solbrig et al, 1996b) and caudateputamen (Solbrig et al, 1998). D2 (but not D1) receptor binding is markedly reduced in caudateputamen; D2 and D3 receptor binding are reduced in nucleus accumbens (Solbrig et al, 1994, 1996a,b). In contrast, postsynaptic dopamine receptors (D1, D2, D3) remain intact in prefrontal cortex (Solbrig et al, 1996a). The basis for this targeted pathogenesis remains unclear; however, within caudate-putamen and nucleus accumbens the postsynaptic dopamine lesions appear to be confined to receptors expressed from spliced messages (D2, D3) rather than unspliced messages (D1). Given that BDV requires the host cell splicing machinery for expression of its genome it has been proposed that competition for splicing machinery may contribute to selective pathology within dopamine circuits (Solbrig et al, 1994).

Although the increased locomotor activity, stereotypic behaviors and dyskinesias of the adult BD model are linked to distinct disturbances in dopaminergic pathways, additional neuromodula- tor abnormalities have been found. Levels of mRNA for somatostatin, cholecystokinin, and glutamic acid decarboxylase are reduced during the acute phase and recover toward normal in the chronic phase of disease (Lipkin et al, 1988). The cholinergic system, a major participant in sensorimotor processing, learning, and memory, also appears to be affected in adult infection. A decrease in the number of choline acetyltransferase-positive fibers has been observed to begin as early as day 6 p.i. and progress to nearly complete loss of cholinergic fibers in hippocampus and neocortex by day 15 p.i. (Gies et al, 1998). Preliminary work on dysregulation of serotonin and norepinephrine systems suggests metabolic hyperactivity of serotonin (as evidenced by modest increase in the metabolite 5-hydroxyindoleacetic acid [5HIAA]) in striatum and of norepinephrine (as evidenced by a small increase in 3-methoxy-4-hydroxyphenethyleneglycol [MHPG]) in prefrontal and anterior cingulate cortex regions (Solbrig et al, 1995). These changes may reflect compensatory upregulation or heterotypic sprouting following partial loss of dopaminergic afferents to these brain regions. Selective effects of BDV on serotonin and norepinephrine pre- or postsynaptic receptors have not yet been investigated. Pharmacological and neurotransmitter-specific molecular probes have also been used to characterize endogenous opioid systems in the adult rat model. Infected animals respond abnormally to the opiate antagonist, naloxone, with hyperkinesis and seizures, and also demonstrate increases in striatal preproenkephalin mRNA at 14 and 21 days (Fu et al, 1993b), and 45 days after BDV infection (Solbrig and Lipkin, personal communication). However, the mechanisms by which these changes in endogenous opioid systems occur are unclear. The marked CNS inflammation in adultinfected rats makes it difficult to determine whether monoamine, cholinergic, and opiatergic dysfunction in $\mathrm{BD}$ results from direct effects of the virus, virus effects on resident cells of the CNS, or a cellular immune response to viral gene products.

It is difficult to establish a direct parallel between the disturbances observed in adult infected rats and a single human CNS disorder because infected rats have an evolving syndrome. Early phases of disease are reminiscent of the hyperactivity observed in bipolar disorder or attention deficit disorder. Such interpretations are interesting historically for their influence on investigators pursuing connections between BDV and human diseases; however, the most compelling aspects of the syndrome from the vantage point of establishing models for human disease instead focus on movement disorders. These simple and complex behaviors clinically and pharmacologically resemble tardive dyskinesia, a common iatrogenic condition that follows use of psychotropic medications, the 'on-off' phenomen- 
on found in late stages of Parkinsonism, and are consistent with some descriptions of postencephalitic Parkinsonism (Solbrig et al, 1999).

\section{Neonatal Lewis rat infection}

Neonatal rat infection may provide an even more intriguing model for neuropsychiatric disorders than adult rat infection. Indeed, the cerebellar and hippocampal dysgenesis that is observed in neonatally-infected animals (Carbone et al, 1991; Narayan et al, 1983a) is consistent with the more subtle neurodevelopmental abnormalities reported by some investigators in autism (Kemper and Bauman, 1993), schizophrenia (Altshuler et al, 1987; Fish et al, 1992), and affective disorders (Soares and Mann, 1997). Neonatally infected animals display a wide range of physiologic and neurobehavioral disturbances. A study of behavioral and cognitive changes in neonatally infected Wistar rats found spatial and aversive learning deficits, increased motor activity, and decreased anxiety responses (Dittrich et al, 1989). Similar deficits in spatial learning and memory were reported in neonatally infected Lewis rats 23-73 days p.i. (Carbone et al, 1996). More recently, play behavior has been reported to be abnormal in the neonatal model, with decreases in both initiation of nondominance-related play interactions and in response to initiation of play by noninfected, age-matched control animals or by infected littermates (Pletnikov et al, 1999). Neonatally infected animals are smaller than uninfected littermates (Carbone et al, 1991; Bautista et al, 1994). The basis for runting is unclear as levels of glucose, growth hormone, and insulin-like growth factor-1 (Bautista et al, 1994) are normal. The amount of food ingested (Bautista et al, 1995) is similar in uninfected and infected rats although the latter have a heightened taste preference for salt solutions (Bautista et al, 1994).

CNS dysfunction in neonatally infected animals has been proposed to be linked to direct viral effects on morphogenesis of the hippocampus and cerebellum, two structures in rodents that continue to develop after birth. Carbone and colleagues found a quantitative relationship of limbic pathology to behavioral abnormalities in the neonatal infection model; the extent of neuronal loss in dentate gyrus appeared to be correlated with the severity of spatial learning and memory deficiencies in neonatallyinfected Lewis rats (Carbone et al, 1996). Although overt ambulatory or cerebellar dysfunction has not been reported (Carbone et al, 1991), we found impairments in balance and coordination during a sensitive dowel-walking task (Hatalski, 1996). Because the cerebellum undergoes substantial postnatal development in many mammals, it is particularly vulnerable to injury from perinatal virus infection (Monjan et al, 1971, 1973; Oster-
Granite and Herdon, 1985). Confirmation of subtle abnormalities in motor coordination in neonatallyinfected rats would provide a functional correlate to anatomic alterations in cerebellum. However, further studies are needed to evaluate the mechanisms by which early postnatal exposure to BDV induces functional damage in either cerebellar or limbic circuitry.

Early reports indicated that there was no cellular inflammatory response following neonatal infection (Carbone et al, 1991; Stitz et al, 1995; Gosztonyi and Ludwig, 1995), a phenomenon ascribed to the immaturity of the rat immune system in the postnatal period. Humoral immune response to BDV in neonatally-infected animals has also been reported to be restricted, with anti-BDV antibody titers remaining below $1: 10$ through 133 days p.i. (Carbone et al, 1991). However, marked astrocytosis has been noted (Carbone et al, 1991; GonzalezDunia et al, 1996; Bautista et al, 1995) in dentate gyrus and cerebellum, suggesting alternate, noninflammatory pathways for glial activation. Higher levels of message for tissue factor (TF) are found in infected hippocampus. TF is a member of the class II cytokine receptor family primarily produced by astrocytes that plays important roles in cellular signal transduction, brain function, and neural development through its effects on coagulation protease cascades. Although this may be one mechanism by which BDV may alter CNS development (Gonzalez-Dunia et al, 1996), cerebellar changes cannot be explained by this mechanism, as $\mathrm{TF}$ upregulation is not observed in cerebellum despite prominent astrocytosis. Furthermore, BDV infection of astrocytes appears to be required for TF upregulation (Gonzalez-Dunia et al, 1996), and cerebellar astrocytes are reported to be spared from BDV infection, at least through 30 days following neonatal infection (Bautista et al, 1995).

Persistent tolerant BDV infection of neonatal rats is linked to hippocampal and cerebellar disorganization (Narayan et al, 1983b; Stitz et al, 1995); however, cytoarchitectonic anomalies in other limbic regions have not been extensively explored. Dentate gyrus involution is evident along with the appearance of reactive glial cells (Carbone et al, 1991), suggesting more direct pathways of viral cytopathic injury. Cerebellar size is reduced, and there is evidence of reactive astrocytosis as demonstrated by glial fibrillary acidic protein (GFAP) reactivity as early as 3 days p.i., preceding the identification of BDV proteins in the cerebellum. Furthermore, reactivity of cerebellar astrocytes and loss of cerebellar granule cells occurs without signs of infection in those cell populations at all timepoints through to 30 days p.i. Curiously, Purkinje cells appeared to be the predominant cerebellar cell population demonstrating BDV proteins, although these cells did not appear to be selectively lost through day 30 p.i. (Bautista et al, 1995). The 
mechanism by which astrocytes are activated in the absence of infection, be it directly by BDV or indirectly through elaboration of soluble factors by other cell types, is not known. Nonetheless, given the role of astrocytes in guiding migration of granule cells during cerebellar development, an assessment of the frequency of astrocyte reactivity in conjunction with studies of apoptosis in limbic structures may elucidate the relative contributions of migrational failure and programmed cell death in pathogenesis of neonatal infection.

Although previous work suggests subtle functional disturbances of limbic circuitry based upon analysis of complex learning behaviors, memory capacities, and emotional responses, the evolution of such disturbances and the mechanisms by which BDV induces their underlying neuropathology without invoking infiltrating inflammatory elements remains to be determined. In an effort to more fully define the nature and unfolding of the neurologic syndrome in neonatally-infected Lewis rats, and to understand the mechanisms of neuropathogenesis in the neonatal model, we established neonatal infection in Lewis rats and serially assessed shifts in neuroanatomy, neurobehavior, and regional gene expression (Hornig et al, 1999).

Locomotor activity and stereotypes were assessed in neonatally infected animals 4,6 and 12 weeks p.i. Results of locomotor activity analyses indicated an overall significant increase in neonatally infected groups relative to controls at all timepoints tested. Analysis of data extrapolated from previous studies of locomotor activity in adult infected animals (Solbrig et al, 1994, 1996b, 1998) revealed that the degree of heightened exploratory locomotor activity found at baseline in neonatally infected animals at 6 and 12 weeks postinfection is greater than in adult infected animals. Locomotor activity across the 90 min observation period differed for all neurally infected groups relative to noninfected controls. At 4 weeks following neonatal infection, animals had prolonged behavioral inhibition upon introduction to the novel environment (first $30 \mathrm{~min}$ interval). These findings are consistent with greater anxiety in novel situations and suggests dysfunction of the amygdala. At the 60 and 90 min intervals, infected animals had greater mean activity measures than controls. Additionally, infected animals showed no attenuation in exploratory activity at 60 and $90 \mathrm{~min}$, consistent with spatial memory deficits and hippocampal dysfunction. Stereotypic behaviors were also increased in neonatally infected groups relative to noninfected controls.

Serial analyses of differential gene expression of cytokines, neurotrophic factors, and apoptosisrelated proteins were pursued by RNase protection assays to assess potential contribution of soluble factors to neuropathogenesis. Possible mechanisms of cytokine-mediated damage in the context of the developing brain include: direct effects on neuronal elements; activation or suppression of second messenger/intracellular signaling pathways; induction of shifts in excitotoxic elements such as quinolinic acid or acute phase proteins such as neopterin or $\beta$-2-microglobulin; direct alterations of neuronal function (e.g., inhibition of long-term potentiation in hippocampus); activation or suppression of glial cells; or alteration of glial cell proliferation or differentiation (including expression of adhesion molecules such as the integrins) (Benveniste, 1997; Mehler et al, 1996). Given that the postnatal expression of neuronotrophic cytokine and cytokine receptor mRNAs in brain differs for each cytokine (Benveniste, 1997), and that the sensitivity of neuronal populations to the trophic or apoptosis-inducing effects of cytokines changes during development, wide variation in the patterns of virus-induced, cytokine-related damage would be expected, depending on the relative maturity of the evolving nervous system at the time of infection. In addition, cell loss induced by either BDV or developmentally-programmed changes may alter the capacity of resident CNS cells to both produce and respond to neuronotrophic cytokines. One means by which a virus might disrupt neural function and development in the absence of inflammation is through the induction of neuronotrophic cytokines. Neuronotrophic cytokines comprise a burgeoning set of immunoregulatory molecules, including the hematolymphoietic factors (e.g., interleukins, tumor necrosis factor family, interferons), the TGF- $\beta$ superfamily factors (including TGF- $\beta 1,2,3$; GDNF), and the classic neurotrophic factors (NGF, BDNF, NT3, NT4/5). A large subset of the neuronotrophic, hematolymphoietic cytokines may be categorized according to their origin from one of two types of T-helper cells: $\mathrm{Th}_{1}$ (cell-mediated immunity and stimulation of antigen-presenting cells) or $\mathrm{Th}_{2}$ (humoral or B-cell mediated immunity).

Brains of infected and noninfected animals were removed at $2,4,6,12$, and 24 weeks p.i. and dissected to collect hippocampus, amygdala, cerebellum, prefrontal cortex, and nucleus accumbens. RNA samples from individual brain regions were subjected to RNase protection assay to quantitate level of transcripts encoding cytokines interleukin (IL)-1 $\alpha$, IL-1 $\beta$, IL-2, IL-3, IL-4, IL-5, IL-6, IL-10, TNF$\alpha$, TNF- $\beta$, IFN- $\gamma$, and TGF- $\beta$ and housekeeping genes L32 and GAPDH. Infected rats had higher levels of mRNAs for cytokine products of CNS macrophages/ microglia (IL-1 $\alpha$, IL-1 $\beta$, IL-6, TNF- $\alpha$ ) in hippocampus, amygdala, cerebellum, prefrontal cortex, and nucleus accumbens. Elevated levels of these proinflammatory cytokines were first apparent at 2 weeks, peaked at 4 weeks, then declined at 6 and 12 weeks. Alterations in other proinflammatory cytokines, including IL-2, IL-3, TNF- $\beta$, and IFN- $\gamma$, were not observed. The fact that cell populations other than macrophages or microglia-T cells, B 
cells, mast cells, bone marrow stromal cells - are the primary sources for the proinflammatory cytokines that remained static following neonatal infection suggests a selective effect of BDV on cells of microglial or macrophage lineage.

Shifts were also observed in gene expression of neurotrophic factors; however, in contrast to the diffuse alterations found in gene expression of cytokine mRNAs, shifts in neurotrophic factor mRNAs were restricted to hippocampus. Decreased mRNAs for BDNF and NT3 were prominent in hippocampus by 4 weeks p.i., but were still evident by 12 weeks p.i. Although decreased NT3 mRNA may reflect loss of the granule cell population in dentate gyrus, the role of BDNF in maintaining viability of cells suggests that its downregulation may be a more essential step in neonatal BDV pathogenesis.

Apoptosis, or programmed cell death, is a mechanism in which cells undergo chromosome condensation, DNA degradation, and morphologic change in the nuclear membrane (Wyllie, 1995). Apoptosis plays an important role in CNS development and response to neuronal injury (Bredesen, 1995). It is conceivable that abnormal regulation of apoptosis, either failure of normal apoptotic sequences to proceed or excessive activity, may contribute to abnormal CNS architecture in neonatal infections with BDV or other neurotropic viruses. Furthermore, apoptosis of antigen-specific lymphocytes might provide an explanation for the immunotolerant state following neonatal BDV infections. Anergy or apoptosis of T cells may result if their stimulation by antigen presenting cells resident to the CNS occurs in the absence of costimulatory signals required for immune activation, such as MHC Class II antigens (Munn et al, 1996). Various stimuli, such as binding of TNF- $\alpha$ to its receptor, can trigger apoptosis; proteins such as the bcl-2 and bax proteins, NF-kappaB and ICErelated proteases have also been shown to play important roles in regulating apoptosis. TNF- $\alpha$ also stimulates apoptosis in a wide variety of cell types (Benveniste, 1997). Furthermore, a host of excitants or neurotoxins including arachidonic acid, plateletactivating factor, free radicals $\left(\mathrm{NO}, \mathrm{O}_{2}{ }^{-}\right)$, glutamate, quinolinate, cysteine, cytokines (TNF- $\alpha$, IL1- $\beta$, IL6 ), amines, and as yet unidentified factors arising from stimulated macrophages and possibly reactive astrocytes may influence apoptosis by excessive activation of N-methyl-D-aspartate (NMDA) receptors (Lipton, 1996). Interestingly, Gosztonyi and Ludwig have proposed that the targeted pathology of BDV for two hippocampal cell layers, stratum oriens and stratum radiatum, may be due to their rich concentration of glutamate and aspartate receptors (Gosztonyi and Ludwig, 1995). Our RNase protection assay analyses revealed complex altera- tions in brain of mRNAs encoding factors associated with apoptosis. Levels of mRNA for FAS and ICE (caspase-1), two promoters of apoptosis, were increased. Levels of mRNA for bcl-x, a factor that inhibits apoptosis, were decreased. Maximal shifts were observed at 4 and 6 weeks p.i., closely paralleling the increases in proinflammatory cytokines noted earlier.

Anatomic studies were consistent with previous reports (Carbone et al, 1991; Narayan et al, 1983b) in demonstrating loss of dentate gyrus granule cells and disorganization of cerebellar granule cell layer. However, new findings included inflammatory cellular infiltrates at week 4 and nearly complete loss of cerebellar Purkinje cells by week 6 . Interestingly, the inflammatory infiltrates were restricted to the motor, parietal and temporal cortex; only rare inflammatory cells were detected in dentate gyrus or cerebellum, the regions where architecture was most disturbed. Terminal deoxynucleotidyl transferase dUTP-biotin nick end labeling (TUNEL) was observed in cerebral cortex and dentate gyrus peaking at 4 weeks p.i. and in granule cell layer of cerebellum of neonatally infected rats at weeks 4 and 6 p.i. Although apoptosis is described in normally developing rat hippocampus as late as day 7 to 10 of postnatal life, it is not found at later timepoints (Toth et al, 1998). The anatomic location of the apoptotic cells and the absence of inflammatory cells in hippocampus and cerebellum suggests that at least some aspects of neuropathology in neonatal infection reflect apoptosis rather than cell-mediated, specific immunity to BDV. Efforts are underway to determine which cells in hippocampus and cerebellum express soluble mediators that might promote apoptosis. Microglial cells are candidates for this activity. Recent studies indicate that they are activated in hippocampus and cerebellum of neonatally infected rats (Hornig et al, 1999).

\section{Summary}

The issue of human BDV infection remains controversial. Nonetheless, recent focus on this intriguing agent has led to establishment of small animal models for studies in BDV pathogenesis that may provide insights into human neuropsychiatric disorders. The two systems presented here, adult and neonatal Lewis rat infection, illustrate the complexities of analyzing neural:immune interactions in a developmental context. Together, they provide powerful tools for exploring the effects of viral and immune factors on CNS development and dynamic models for parsing the anatomy, pharmacology and neurochemistry of specific neuropsychiatric syndromes. 


\section{References}

Altshuler LL, Conrad A, Kovelman JA, Scheibel A (1987). Hippocampal pyramidal cell orientation in schizophrenia: a controlled neurohistologic study of the Yakovlev Collection. Arch Gen Psychiatry 44: 1094-1098.

Amsterdam J, Winokur A, Dyson W, Herzog S, Gonzalez F, Rott R, Koprowski H (1985). Borna Disease Virus: a possible etiologic factor in human affective disorders. Arch Gen Psychiatry 42: $1093-1096$.

Anderson GM (1994). Studies on the neurochemistry of autism. In: The Neurobiology of Autism. Bauman ML, Kemper TL (eds). Johns Hopkins University Press: Baltimore, pp 227-242.

Bautista JR, Rubin SA, Moran TH, Schwartz GJ, Carbone KM (1995). Developmental injury to the cerebellum following perinatal Borna disease virus infection. Dev Brain Res 90: 45-53.

Bautista JR, Schwartz GJ, de la Torre JC, Moran TH, Carbone KM (1994). Early and persistent abnormalities in rats with neonatally acquired Borna disease virus infection. Brain Res Bull 34: 31-40.

Benveniste EN (1997). Cytokine expression in the nervous system. In: Immunology of the Nervous System. Keane RW, Hickey WF (eds). Oxford University Press: New York, pp. 419-459.

Bode L, Ferszt R, Czech G (1993). Borna disease virus infection and affective disorders in man. Arch Virol 7: $159-167$.

Bode L, Riegel S, Lange W, Ludwig H (1992). Human infections with Borna disease virus: seroprevalence in patients with chronic diseases and healthy individuals. J Med Virol 36: 309-315.

Bode L, Riegel S, Ludwig H, Amsterdam J, Lange W, Koprowski H (1988). Borna disease virus-specific antibodies in patients with HIV infection and with mental disorders. Lancet ii: 689.

Bredesen D (1995). Neural apoptosis. Ann Neurol 38: 839-851.

Buchmeier MJ, Lewicki HA, Talbot PJ, Knobler RL (1984). Murine hepatitis virus-4 (strain JHM)-induced neurologic disease is modulated in vivo by monoclonal antibody. Virology 132: $261-270$.

Carbone K, Park S, Rubin S, Waltrip R, Vogelsang G (1991). Borna disease: association with a maturation defect in the cellular immune response. J Virol 65: 6154-6164.

Carbone KM, Duchala CS, Griffin JW, Kincaid AL, Narayan O (1987). Pathogenesis of Borna disease in rats: evidence that intra-axonal spread is the major route for virus dissemination and the determinant for disease incubation. J Virol 61: 3431-3440.

Carbone KM, Silvas PM, Rubin SA, Vogel M, Moran TH, Schwartz G (1996). Quantitative correlation of viral induced damage to the hippocampus and spatial learning and memory deficits. J Neurovirol 2: 195.

Cooper JR, Bloom FE, Roth RH (1991). The Biochemical Basis of Neuropharmacology. Oxford University Press: New York, pp. 332-334.

de la Torre JC (1994). Molecular biology of Borna disease virus: prototype of a new group of animal viruses. $J$ Virol 68: $7669-7675$.
Dietzschold B, Kao M, Zheng YM, Chen ZY, Maul G, Fu ZF, Rupprecht CE, Koprowski H (1992). Delineation of putative mechanisms involved in antibody-mediated clearance of rabies virus from the central nervous system. Proc Natl Acad Sci USA 89: 7252-7256.

Dittrich W, Bode L, Ludwig H, Kao M, Schneider K (1989). Learning deficiencies in Borna disease virusinfected but clinically healthy rats. Biol Psychiatry 26: $818-828$.

Ernst M, Zametkin AJ, Matochik JA, Pascualvaca D, Cohen RM (1997). Low medial prefrontal dopaminergic activity in autistic children. Lancet 350: 638.

Fish B, Marcus J, Hans SL, Auerbach JG, Perdue S (1992). Infants at risk for schizophrenia: sequelae of a genetic neurointegrative defect: a review and replication analysis of pandysmaturation in the Jerusalem Infant Development Study. Arch Gen Psychiatry 49: $221-235$

Fu ZF, Amsterdam JD, Kao M, Shankar V, Koprowski H, Dietzschold B (1993). Detection of Borna disease virus-antibodies from patients with affective disorders by western immunoblot technique. J Affect Disord 27: $61-68$.

Fu ZF, Weihe E, Zheng YM, Schafer MKH, Sheng H, Corisdeo S, Rauscher III FJ, Koprowski H, Dietzschold B (1993b). Differential effects of rabies and Borna Disease viruses on immediate-early- and late-gene expression in brain tissues. J Virol 67: 6674-6681.

Gies U, Bilzer T, Stitz L, Staiger JF (1998). Disturbance of the cortical cholinergic innervation in Borna disease prior to encephalitis. Brain Pathol 8: 39-48.

Gonzalez-Dunia D, Eddleston M, Mackman N, Carbone KM, de la Torre JC (1996). Expression of tissue factor is increased in astrocytes within the central nervous system during persistent infection with Borna disease virus. J Virol 70: $5812-5820$.

Gosztonyi G, Ludwig H (1995). Borna disease: neuropathology and pathogenesis. In: Current Topics in Microbiology \& Immunology, Vol. 190: Borna Disease. Koprowski H, Lipkin WI (eds). Springer-Verlag: Berlin, pp. 39-73.

Hamner MB, Diamond BI (1996). Plasma dopamine and norepinephrine correlations with psychomotor retardation, anxiety, and depression in non-psychotic depressed patients: a pilot study. Psychiatry Res 64: $209-211$

Hatalski CG (1996). Alterations in the immune response within the central nervous system of rats infected with Borna disease virus: potential mechanisms for viral persistence. Ph.D. Thesis, University of California Irvine.

Hatalski CG, Hickey WF, Lipkin WI (1998a). Evolution of the immune response in the central nervous system following infection with Borna disease virus. J Neuroimmunol 90: 137-142.

Hatalski CG, Hickey WF, Lipkin WI (1998b). Humoral immunity in the central nervous system of Lewis rats infected with Borna disease virus. J Neuroimmunol 90: $128-136$. 
Hornig M, Solbrig M, Weissenböck H, Lipkin WI (1999). Mechanisms of central nervous system dysfunction in Bornavirus infected rats. Current Topics in Microbiology \& Immunology, Mechanisms of Neuronal Damage in Viral Infections of the Nervous System. Goztonyi G (ed). Springer-Verlag: Heidelberg, In Press.

Iwata Y, Takahashi K, Peng X, Fukuda K, Ohno K, Ogawa T, Gonda K, Mori N, Niwa S, Shigeta S (1998). Detection and sequence analysis of borna disease virus p24 RNA from peripheral blood mononuclear cells of patients with mood disorders or schizophrenia and of blood donors. J Virol 72: 10044-10049.

Karpas WJ, Peterson JD, Miller SD (1994). Anergy in vivo: down regulation of antigen-specific CD4+ Th1 but not Th2 cytokine responses. Int Immunol 6: 721 730.

Kelsoe JR, Sadovnick AD, Krisbjarnarson H, Bergesch P, Mroczkowski-Parker Z, Drennan M, Rapaport MH, Flodman P, Spence MA, Remick RA (1996). Possible locus for bipolar disorder near the dopamine transporter on chromosome 5. Am J Med Genet 67: 533540.

Kemper TL, Bauman ML (1993). The contribution of neuropathologic studies to the understanding of autism. Neurol Clin North Am 11: 175-187.

Khoury SJ, Akalin E, Chandraker A, Turka LA, Linsley PS, Sayegh MH, Hancock WW (1995). CD28-B7 costimulatory blockade by CTLA4Ig prevents actively induced experimental autoimmune encephalomyelitis and inhibits Th1 but spares Th2 cytokines in the central nervous system. J Immunol 155: 4521-4524.

Kishi M, Nakaya T, Nakamura Y, Zhong Q, Iketa K, Sengo M, Kakinuma M, Kato S, Ikuta K (1995). Demonstration of human Borna disease virus RNA in human peripheral blood mononuclear cells. FEBS Lett 364: $293-297$.

Kubo K, Fujiyoshi T, Yokoyama MM, Kamei K, Richt JA, Kitze B, Herzog S, Takigawa M, Sonoda S (1997). Lack of association of Borna disease virus and human T-cell leukemia virus type 1 infections with psychiatric disorders among Japanese patients. Clin Diagn Lab Immunol 4: 189-194.

Levine B, Hardwick JM, Trapp BD, Crawford TO, Bollinger RC, Griffin DE (1991). Antibody-mediated clearance of alphavirus infection from neurons. Science 254: 856-860.

Lieb K, Hallensleben W, Czygan M, Stitz L, Staeheli P (1997). No Borna disease virus-specific RNA detected in blood from psychiatric patients in different regions of Germany. The Bornavirus Study Group. Lancet 350: 1002.

Liebert UG, Schneider-Schaulies S, Baczko K, ter Meulen $\mathrm{V}$ (1990). Antibody-induced restriction of viral gene expression in measles encephalitis in rats. J Virol 64: $706-713$.

Lipkin WI, Carbone KM, Wilson MC, Duchala CS, Narayan O, Oldstone MBA (1988). Neurotransmitter abnormalities in Borna disease. Brain Res 475: $366-$ 370.

Lipkin WI, Schneemann A, Solbrig MV (1995). Borna disease virus: implications for human neuropsychiatric illness. Trends Microbiol 3: 64-69.
Lipton SA (1996). Similarity of neuronal cell injury and death in AIDS dementia and focal cerebral ischemia: potential treatment with NMDA open-channel blockers and nitric oxide-related species. Brain Pathol 6: $507-517$.

Ludwig H, Bode L, Gosztonyi G (1988). Borna disease: a persistent disease of the central nervous system. Prog Med Virol 35: 107-151.

Mehler MF, Goldstein H, Kessler JA (1996). Effects of cytokines on CNS cells: neurons. In: Cytokines and the CNS. Ransohoff RM, Benveniste EN (eds). CRC Press: Boca Raton, pp 115-150.

Monjan AA, Cole GA, Gilden DH, Nathanson N (1973). Pathogenesis of cerebellar hypoplasia produced by lymphocytic choriomeningitis virus infection of neonatal rats: evolution of disease following infection at 4 days of age. J Neuropathol Exp Neurol 32: 110-124.

Monjan AA, Gilden DH, Cole GA, Nathanson N (1971). Cerebellar hypoplasia in neonatal rats caused by lymphocytic choriomeningitis virus. Science 171: 194-196.

Munn DH, Pressey J, Beall AC, Hudes R, Alderson MR (1996). Selective activation-induced apoptosis of peripheral $\mathrm{T}$ cells imposed by macrophages: a potential mechanism of antigen-specific peripheral lymphocyte deletion. J Immunol 156: 523-532.

Narayan O, Herzog S, Frese K, Scheefers H, Rott R (1983a). Behavioral disease in rats caused by immunopathological responses to persistent Borna virus in the brain. Science 220: 1401-1403.

Narayan O, Herzog S, Frese K, Scheefers H, Rott R (1983b). Pathogenesis of Borna disease in rats: immune-mediated viral ophthalmoencephalopathy causing blindness and behavioral abnormalities. I Inf Dis 148: $305-315$.

Oster-Granite ML, Herdon RM (1985). The pathogenesis of parvovirus-induced cerebellar hypoplasia in the Syrian hamster, Mesociretus auratus: fluorescent antibody, foliation, cytoarchitectonic, golgi and electron microscopic studies. J Comp Neurol 169: 481-522.

Partonen T (1996). Dopamine and circadian rhythms in seasonal affective disorder. Med Hyp 47: 191-192.

Pletnikov MV, Rubin SA, Vasudevan K, Moran TH, Carbone KM (1999). Developmental brain injury associated with abnormal play behavior in neonatally Borna disease virus (BDV)-infected rats: a model of autism. Behavioral Brain Res 100: 43-50.

Richt JA, Alexander RC, Herzog S, Hooper DC, Kean R, Spitsin S, Bechter K, Schuttler R, Feldmann H, Heiske A, Fu ZF, Dietzschold B, Rott R, Koprowski H (1997). Failure to detect Borna disease virus infection in peripheral blood leukocytes from humans with psychiatric disorders. J Neurovirol 3: 174-178.

Rubin SA, Sierra-Honigmann AM, Lederman HM, Waltrip II RW, Eiden JJ, Carbone KM (1995). Hematologic consequences of Borna disease virus infection of rat bone marrow and thymus stromal cells. Blood 85: 2762-2769. 
Saito N, Itouji A, Totani Y, Osawa I, Koide H, Fujisawa N, Ogita K, Tanaka C (1993). Cellular and intracellular localization of epsilon-subspecies of protein kinase C in the rat brain; presynaptic localization of the epsilon-subspecies. Brain Res 607: 241-248.

Schneemann A, Schneider PA, Lamb RA, Lipkin WI (1995). The remarkable coding strategy of Borna disease virus: a new member of the nonsegmented negative strand RNA viruses. Virology 210: 1-8.

Schwartz RH (1992). Costimulation of $\mathrm{T}$ lymphocytes: the role of CD28, CTLA-4 and B7/BB1 in interleukin-2 production and immunotherapy. Cell 71: 1065-1068.

Schwemmle M, De B, Shi L, Banerjee A, Lipkin WI (1997). Borna Disease Virus P-protein is phosphorylated by protein kinase $\mathrm{C} \varepsilon$ and casein kinase II. J Biol Chem 272: 21818-21823.

Schwemmle M, Salvatore M, Shi L, Richt J, Lee CH, Lipkin WI (1998). Interactions of the Borna disease virus $\mathrm{P}, \mathrm{N}$, and $\mathrm{X}$ proteins and their functional implications. J Biol Chem 273: $9007-9012$.

Schwemmle M, Jehle C, Shoemaker T, Lipkin WI (1999). Characterization of the major nuclear localization signal of the Borna disease virus phosphoprotein. J Gen Virol 80: 97-100.

Shoya Y, Kobayashi T, Koda T, Ikuta K, Kakinuma M, Kishi M (1998). Two proline-rich nuclear localization signals in the amino- and carboxyl-terminal regions of the Borna disease virus phosphoprotein. J Virol $\mathbf{7 2}$ 9755-9762.

Soares JC, Mann JJ (1997). The anatomy of mood disorders-review of structural neuroimaging studies. Biol Psychiatry 41: 86-106.

Sobbe M, Bilzer T, Gommel S, Noske K, Planz O, Stitz L (1997). Induction of degenerative brain lesions after adoptive transfer of brain lymphocytes from Borna disease virus-infected rats: presence of CD8+ T cells and perforin mRNA. I Virol 71: 2400-2407.

Solbrig MV, Fallon JH, Lipkin WI (1995). Behavioral disturbances and pharmacology of Borna disease virus. In: Current Topics in Microbiology \& Immunology, Vol. 190: Borna Disease. Koprowski H, Lipkin WI (eds). Springer-Verlag: Heidelberg, pp 93-101.
Solbrig MV, Koob GF, Fallon JH, Lipkin WI (1994). Tardive dyskinetic syndrome in rats infected with Borna disease virus. Neurobiol Dis 1: 111-119.

Solbrig MV, Koob GF, Fallon JH, Reid S, Lipkin WI (1996a). Prefrontal cortex dysfunction in Borna disease virus (BDV)-infected rats. Biol Psychiatry 40: $629-636$.

Solbrig MV, Koob GF, Joyce JN, Lipkin WI (1996b). A neural substrate of hyperactivity in Borna disease: changes in dopamine receptors. Virology 222: $332-$ 338.

Solbrig MV, Koob GF, Lipkin WI (1998). Cocaine sensitivity in Borna disease virus infected rats. Pharmacol Biochem Behav 59: 1047-1052.

Solbrig MV, Koob GF, Lipkin WI (1999). Orofacial dyskinesia and dystonia in rats infected with Borna disease virus: a model for tardive dyskinetic syndromes. Mol Psychiatry In Press.

Stitz L, Dietzschold B, Carbone KM (1995). Immunopathogenesis of Borna disease. In: Current Topics in Microbiology \& Immunology, Vol. 190: Borna Disease. Koprowski H, Lipkin WI (eds). Springer-Verlag: Heidelberg, pp 75-92.

Stitz L, Krey H, Ludwig H (1980). Borna disease in rhesus monkeys as a model for uveo-cerebral symptoms. J Med Virol 6: 333-340.

Stitz L, Nöske K, Planz O, Furrer E, Lipkin WI, Bilzer T (1998). A functional role for neutralizing antibodies in Borna disease: influence on virus tropism outside the central nervous system. J Virol 72: 8884-8892.

Toth Z, Yan XX, Haftoglou S, Ribak CE, Baram TZ (1998). Seizure-induced neuronal injury: vulnerability to febrile seizures in an immature rat model. $J$ Neurosci 18: $4285-4294$

Waltrip II RW, Buchanan RW, Summerfelt A, Breier A, Carpenter WT, Bryant NL, Rubin SA, Carbone K (1995). Borna disease virus and schizophrenia. Psychiatry Res 56: $33-44$.

Wyllie AH (1995). The genetic upregulation of apoptosis. Curr Opin Genet Dev 5: 97-104. 